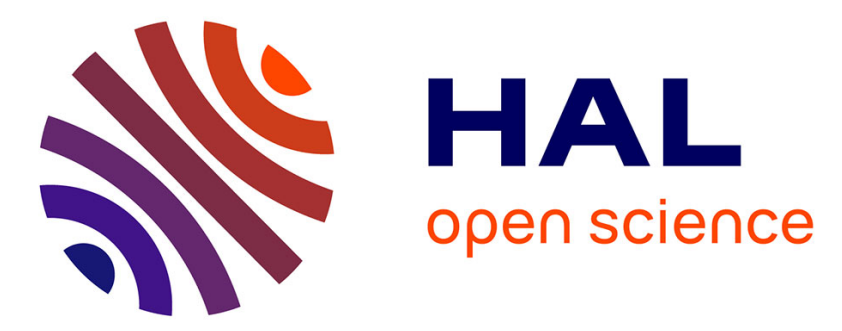

\title{
Optimized laminations for submarine composite hulls
} Tanguy Messager, Mariusz Pyrz, Pierre Chauchot

\section{To cite this version:}

Tanguy Messager, Mariusz Pyrz, Pierre Chauchot. Optimized laminations for submarine composite hulls. Revue Européenne des Éléments Finis, 2000, 9 (1 2 3), pp.199-215. 10.1080/12506559.2000.10511436 . hal-01007167

\section{HAL Id: hal-01007167 \\ https://hal.science/hal-01007167}

Submitted on 24 Nov 2016

HAL is a multi-disciplinary open access archive for the deposit and dissemination of scientific research documents, whether they are published or not. The documents may come from teaching and research institutions in France or abroad, or from public or private research centers.
L'archive ouverte pluridisciplinaire HAL, est destinée au dépôt et à la diffusion de documents scientifiques de niveau recherche, publiés ou non, émanant des établissements d'enseignement et de recherche français ou étrangers, des laboratoires publics ou privés. 


\section{Optimized laminations for submarine composite hulls}

\section{Tanguy Messager $^{*}$ - Mariusz Pyrz ${ }^{* *}$ - Pierre Chauchot ${ }^{* * *}$}

* Laboratoire de Rhéologie et de Mécanique des Structures, EA 940

Université de Bretagne Occidentale

6 av. Le Gorgeu, BP 809, F-29285 Brest cedex

Tanguy.Messager@univ-brest.fr

** Laboratoire de Mécanique de Lille, URA CNRS 1441

Bd Paul Langevin, F-59655 Villeneuve d'Ascq cedex

Mariusz.Pyrz@eudil.fr

*** IFREMER, Service Matériaux et Structures

BP 70, F-29280 Plouzané

Chauchot@ifremer.fr

ABSTRACT: This work deals with the development of a numerical tool for the design of filament wound submersible composite cylinders. A genetic algorithm coupled with analytical shell models allows stacking sequences to be optimized in order to increase the buckling pressures. The examples presented concern IFREMER's current studies and characteristic lamination patterns have been obtained. FEM calculations confirm the gains corresponding to the solutions obtained. The robustness of the optimized laminations is attentively studied. The performances of the optimization procedure are also discussed.

RESUMÉ : Ce travail concerne l'élaboration d'un outil numérique d'aide à la conception d'enceintes sous-marines cylindriques composites réalisées par enroulement filamentaire. Un algorithme génétique couplé à des modèles analytiques des coques permet d'en optimiser la stratification afin d'accroître la limite de flambage. Les applications présentées sont liées aux travaux actuels de l'IFREMER. Les calculs d'optimisation ont conduit à l'obtention d'un type de stratification caractéristique. Les calculs MEF confirment l'intérêt des solutions optimisées. Une attention particulière est accordée à l'étude de la robustesse de ces solutions. De plus, les performances de la procédure d'optimisation sont analysées.

KEY WORDS: cylinders, buckling, composite materials, laminations, optimization, genetic algorithm.

MOTS-CLÉs: cylindres, flambage, matériaux composites, stratifications, optimisation, algorithme génétique. 


\section{Introduction}

The use of composite materials in the manufacturing of submersible structures allows low weight to displacement ratios and long endurance for devices of limited energy carrying capability [VIN 92] [GRA 95]. Various potential applications, such as autonomous underwater vehicles and submarine exploration hulls, are currently developed by IFREMER with participation in European BRITE and MAST programs [DAV 96]. Figure 1 presents an application with a towed acoustic sonar. The cylindrical hulls used for such structures are composed of multilayered thin or medium-thick composite cylinders, obtained by the filament winding process [DVO 96], and closed by rigid metallic end-closures as shown in Figure 2. Experimental tests of cylindrical highly pressurized hulls (60 MPa service pressure) have been carried out by IFREMER. These tests, validated by numerical studies using FEM models, have confirmed the risk of failure due to buckling caused by the external hydrostatic pressure [DAV 96].

All cylinders investigated so far used orthotropic $\left[ \pm 55^{\circ}{ }_{N}\right]$ (angles measured with respect to the cylinder axis) stacking sequences. This choice is due to the ratio between the circumferential and the axial load components resulting from the pressure [GAY 97]. Such a lamination pattern, classical for thin tubes submitted to internal hydrostatic pressure, does not take into account the instability risk.

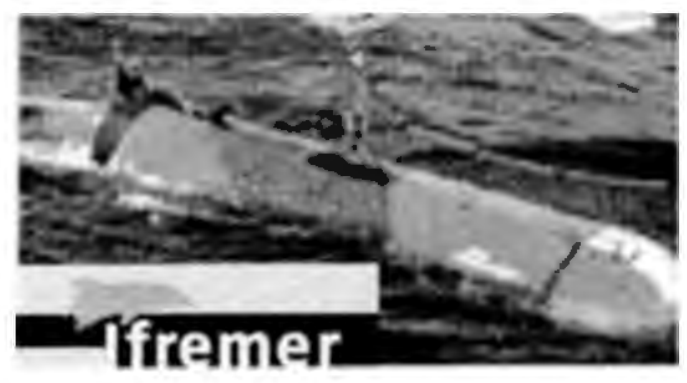

Figure 1. Example of application

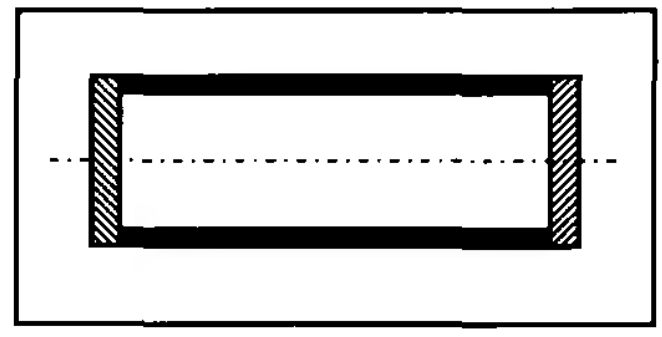

Figure 2. Cylindrical hull

This paper deals with an optimal design tool for submersible composite cylinders, allowing the search for lamination patterns that increase the buckling pressure $P_{c r}$. The approach developed consists in coupling analytical models of cylindrical composite shell buckling with an optimization procedure based on a genetic algorithm directly manipulating the integer design parameters. The numerical applications presented, including specific manufacturer constraints, are connected with IFREMER's current studies. FEM models are applied to verify the stability limit increases corresponding to optimized stacking sequences. The performances of the optimization procedure are studied. Moreover, the robustness of the optimized solution patterns is also enhanced by analyzing the influences of the material characteristic values and the geometrical imperfections. 


\section{Cylinder modeling}

The geometry of the cylindrical shell is characterized by the length $L$, its meanradius $R$ and the wall-thickness $h$. As shown in figure 3, the $u, v$ and $w$ displacements are expressed in the $(x, y, z)$ coordinate system related to the cylindrical mid-surface. Each $k^{\text {th }}$ composite layer characterized by the filament winding angle noticed $\theta_{k}$ (measured in degrees with respect of the cylinder axis) is cross-ply, i.e. made up of equal amounts of fibers in the $+\theta_{k}$ and $-\theta_{k}$ directions. According to previous modeling studies [GUG 95] [PAP 98], the cylinders are assumed to be simply supported at their ends.

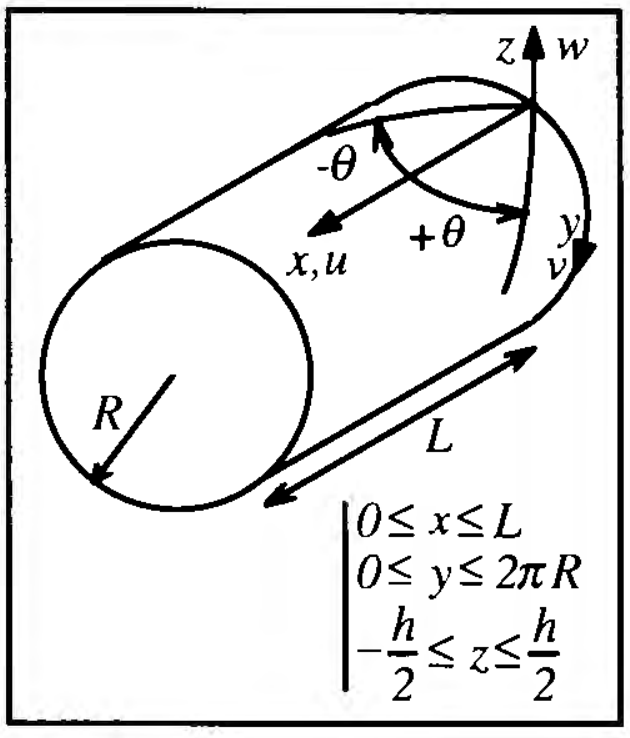

Figure 3. Geometry and coordinate system

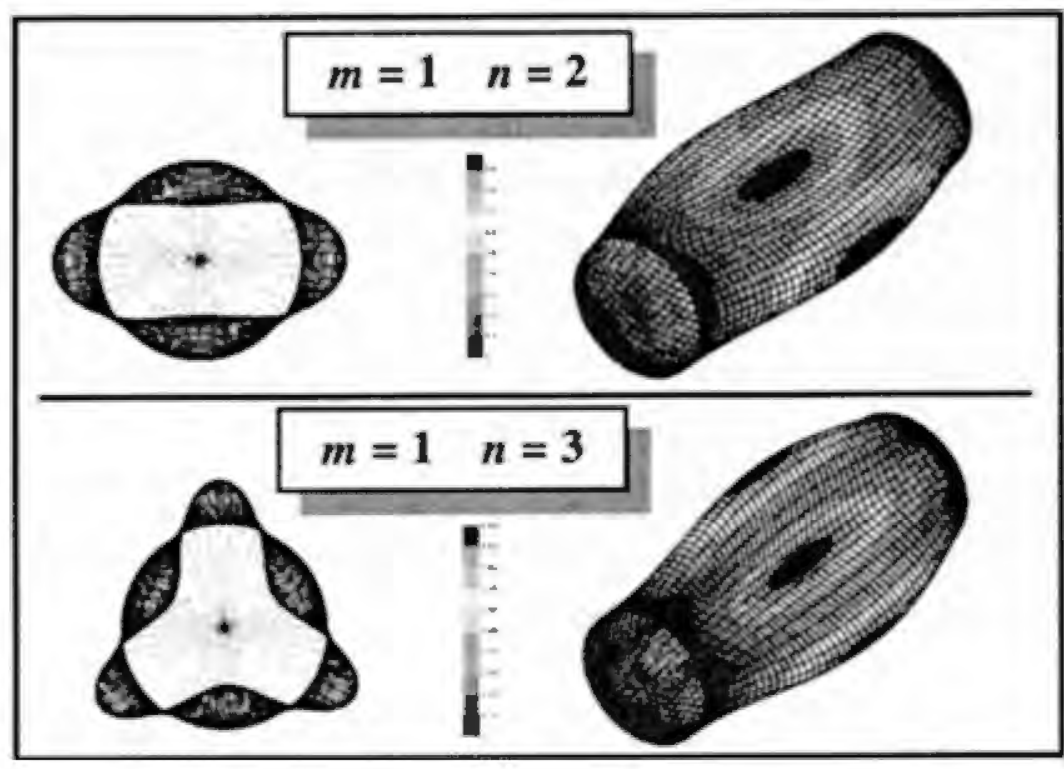

Figure 4. Buckling mode shapes

\subsection{Analytical models}

Two analytical models for the buckling of laminated cylinders have been developed and coupled with the optimization procedure:

- a Sanders-type (also called Love-type) model which neglects the transverse shear effects [BAR 83],

- a model based on a third order shear deformation theory called CT3.

The basic strain-displacement relations and the equilibrium equations are detailed in [MES 99]. The displacement approximation functions, characterizing buckling modes and corresponding to simply supported kinematic boundary conditions at the ends of the cylinders, are expressed in the following form [BAR 83]:

$$
\left\{\begin{array} { l } 
{ u = \operatorname { c o s } ( \overline { m } x ) \operatorname { c o s } ( \overline { n } y ) } \\
{ v = \operatorname { s i n } ( \overline { m } x ) \operatorname { s i n } ( \overline { n } y ) } \\
{ w = \operatorname { s i n } ( \overline { m } x ) \operatorname { c o s } ( \overline { n } y ) }
\end{array} \text { with } \quad \left\{\begin{array}{l}
\bar{m}=m \pi / L \\
\bar{n}=n / R
\end{array}\right.\right.
$$


where $m$ and $n$ are the number of longitudinal and circumferential half waves respectively. It is worth noting that for all applications investigated in this study, buckling modes have been always characterized by $m=1$ and $n=2$ or $n=3$, similarly to the examples presented in figure 4 .

The geometrical imperfections are the main source of buckling load reductions for both isotropic and composite thin-walled cylinders under hydrostatic pressure [TAB 97]. These geometric defects lead to considerable discrepancies (sometimes exceeding 50\%) between experimental results and perfect cylinder model predictions [BAR 83]. For several years, many authors have studied and developed analytical models of imperfect laminated cylinders subjected to buckling. Those formulations have been based on two main features [TEN 71]:

- The geometrical imperfection is modelled by an axisymetric, waving, modal deflection of the mid-surface of the cylinder. This assumption is an extension of previous analysis, concerning the buckling of isotropic imperfect cylinders.

- The geometrical defect effects are assumed to be of the second order. Only the nonlinear terms of deformation take into account this modal imperfection. This assumption leads to complex nonlinear formulation, then requiring specific and expensive solving procedures.

A new formulation was developed for our study: by analogy to their real shapes [DVO 96], each ply is assumed to have a thickness defect modeled by an axisymetric modal waviness defined as:

$$
\tilde{w}=\tilde{a} \sin (\tilde{m} \pi x / L)
$$

where $\tilde{a}$ is the equivalent maximum imperfection amplitude related to each ply. As for the classical imperfection modeling [TEN 71], [BAR 83], the number of the longitudinal half waves $\tilde{m}$ is related to $m$. The global geometrical imperfection of the cylinder is then assumed to be generated by all of these ply defects. The effects of the ply imperfections are introduced in the problem by correcting the stiffness coefficients of the laminate. The final linear form of the eigen-value problem of buckling is obtained using Galerkin's method. The formulation of these geometrical imperfection models, tests and comparisons with FEM results are detailed in [MES 99].

\subsection{FE models}

The finite element modeling has been performed in order to verify the critical load increases for optimized stacking sequences. A linear analysis of stability has been carried out using the Samcef FEM code for three types of composite laminated shell elements: hybrid (neglecting the shear transverse effects), Mindlin and volume elements. The rigid end-closures were modelled by rigid body elements leading to simply supported boundary conditions [GUG 95] [PAP 98]. Moreover, the hybrid shell element model allows the buckling analysis of geometrically imperfect 
cylinders. As for the most part of the standard FEM codes, the global geometrical imperfection is modeled by introducing a modal deviation in the coordinate values of the nodes.

Independently, calculus has been performed using the Adina code and FE model, similar to the Samcef Mindlin one. Moreover, some comparisons have been realized applying a laminated shell element (neglecting the transverse shear effects) of the Solvia FEM code [PAP 98].

\section{Optimization procedure}

\subsection{GAs principle}

Among several computational techniques developed to deal with discrete engineering optimization problems, the promising applications of Genetic Algorithms (GAs) have been explored intensively in recent years. GAs are a class of computational models inspired by evolution, which may be used directly to solve non differentiable and discontinuous problems. They are particularly effective in the case of many locally optimal points. Numerous recent applications of GA to various engineering problems presented in the literature have shown the usefulness of this class of search procedures. The standard GA manipulates a fixed number of individuals, each corresponding to a potential solution of the optimization problem. A measure of performance, called fitness and corresponding to the objective function, is associated with each of them. The starting population is randomly created. The process of evolution is simulated using a set of biologically inspired operators (selection, crossover and mutation). Accordingly to evolutionary theories, the most suited elements, having the higher fitness values, are likely to survive and to produce next generations of "children" by recombining the features of "parents". Then, each iterative step creates a new generation of possible solutions. Finally, the GA sends back the best individual. This simulated evolution process is detailed for example in [GOL 94], [MIC 96] and [SEB 96].

\subsection{Variable encoding and genetic operators}

For a large majority of GAs applications in structural optimization, the design parameters are binary encoded and manipulated as bit strings called chromosomes [GOL 94]. This technique seems to be quite natural in many problems, for example in the case of topological optimization, where a value of binary gene can indicate the presence or absence of material in a given part of a structure [PYR 98]. Some authors [SEB 96] mention however a risk of processing of binary encoded variables due to epistasis phenomenon [MIC 96]. For the present study an "integer" version of GA, manipulating directly integer parameters, has been created. The whole arithmetical crossover operator is applied. This technique is defined as 
follows, where $\vec{x}_{1}$ and $\vec{x}_{2}$ are "parents", and $\vec{x}_{1}^{\prime}$ and $\vec{x}_{2}^{\prime}$ are the corresponding "children":

$$
\left\{\begin{array}{l}
\vec{x}_{1}^{\prime}=\operatorname{Int}\left[r \vec{x}_{1}+(1-r) \vec{x}_{2}\right] \\
\vec{x}_{2}^{\prime}=\operatorname{Int}\left[r \vec{x}_{2}+(1-r) \vec{x}_{1}\right]
\end{array}\right. \text { with }
$$

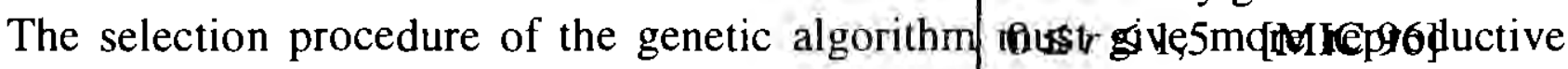
chances to the more fit individuals. The created GA applies the tournament procedure [SEB 96]: the bettern one of two individuals randomly selected is then chosen. This technique, inducing a constant selective pressure [SEB 96], can enhance efficiently GA search [YAN 97]. The elitist selection technique is used and the best chromosome is automatically reproduced in the next generation. Moreover, the random uniform mutation [MIC 96] is applied.

\section{Numerical applications}

\subsection{Cylinders considered}

The applications presented concern IFREMER's current studies carried out in connection with the manufacturer CNIM (Constructions Navales Industrielles de la Méditérannée). The structures considered are small scale cylinders having a $400 \mathrm{~mm}$ length and a $175 \mathrm{~mm}$ internal diameter. The material is a carbon fiber reinforced epoxy resin. According to previous experimental and numerical studies [DAV 96] [PAP 98], the following orthotropic mechanical properties are considered (modulus in GPa): $E_{1}=156 ; E_{2}=9.65 ; E_{3}=6.57 ; G_{12}=5.473 ; G_{13}=2.8 ; G_{23}=3.925 ; v_{12}=0.27$; $v_{13}=0.34 ; v_{23}=0.492$. Each cross-ply is about $0.624 \mathrm{~mm}$ thick [PAP 98]. Six cylinders, thin-walled and half-thick, are investigated. Table 1 presents the corresponding numbers of plies and thicknesses.

Table 2 shows values of critical pressure, calculated using both the analytical and FE models, for the initial cylinders having $\left[55_{N}\right]$ lamination pattern. As mentioned in $\S 2.1$, buckling modes obtained from FE and analytical models always match one of the shapes presented in Figure 4. For the thicker cylinders, the shear transverse effects appear to have a great influence on the buckling pressure calculated using FE models. The results corresponding to the Sanders-type model are always similar to the CT3 ones. However, these values are lower than the FE results for the thinner cylinders and higher for the thickest.

\begin{tabular}{|c||c|c|c|c|c|c|}
\hline cylinder number & $\mathbf{1}$ & $\mathbf{2}$ & $\mathbf{3}$ & $\mathbf{4}$ & $\mathbf{5}$ & $\mathbf{6}$ \\
\hline number of plies $\boldsymbol{N}$ & 10 & 13 & 16 & 19 & 26 & 32 \\
\hline thickness $\boldsymbol{h}(\mathbf{m m})$ & 6.2 & 8.1 & 10.0 & 11.9 & 16.2 & 20.0 \\
\hline
\end{tabular}




\begin{tabular}{|c|c|c|c|c|c|c|c|}
\hline \multicolumn{1}{c|}{ cylinder $^{\circ}$} & $\mathbf{1}$ & $\mathbf{2}$ & $\mathbf{3}$ & $\mathbf{4}$ & $\mathbf{5}$ & $\mathbf{6}$ \\
\hline Sanders & 17.0 & 31.1 & 51.2 & 78.5 & 173.3 & 295.5 \\
\cline { 2 - 8 } & CT3 & 17.0 & 31.1 & 51.4 & 78.9 & 174.3 & 297.1 \\
\hline \multirow{P}{Pcr}{$(\mathbf{M P a})$} & Samcef hybrid & 20.0 & 41.7 & 65.4 & 91.3 & 175.3 & 275.8 \\
\cline { 2 - 8 } & Samcef Mindlin & 18.4 & 35.2 & 57.5 & 83.4 & 145.1 & 207.5 \\
\cline { 2 - 8 } & Samcef volume & 18.5 & 35.6 & 59.8 & 75.8 & 133.6 & 195.2 \\
\hline & Adina & 21.3 & 41.4 & 68.2 & 102.0 & $\times$ & $\times$ \\
\hline & Solvia & 19.0 & 38.6 & 65.8 & 99.2 & $\times$ & 258.6 \\
\hline
\end{tabular}

Table 2. Buckling pressures of the $\left[55_{N}\right]$ cylinders

\subsection{Optimization results}

\subsubsection{Solutions including manufacturing constraints}

The optimization problem is formulated as follows:

find: $\left[\theta_{1} / \theta_{2} / \ldots / \theta_{N}\right]_{O P T I}$ to maximize the objective function: $F=P_{c r}$

According to the manufacturer constraints, the filament winding angle values are subjected to the five following values (expressed in degrees):

$$
\theta_{i} \in\{30 ; 45 ; 60 ; 75 ; 90\}
$$

For each thickness case investigated and for each analytical model used, 20 runs of GA program were performed. The following values of GA operator probabilities [GOL 94] have been applied in the optimization codc: $80 \%$ for crossover and $0.8 \%$ for mutation. The numbers of individuals and numbers of generations are detailed in $\S 4.3$. The best stacking sequences (leading to greater $P_{c r}$ values) obtained using the Sanders and the CT3 models coupled to the GA are presented in figure 5 and 6 , respectively. In these figures, the lamination plies are numbered from the inner to the outer surface of the cylinder. For each optimized stacking sequences, a table presents the critical pressures values calculated using different analytical and Samcef models. The shapes of buckling modes are similar to those presented in Figure 4. The increase of critical pressure, deducted from optimized stacking sequences (with respect to the $\left[55_{N}\right]$ initial solutions), is evaluated using the gain $G$ and the nondimensionalized gain factor $\gamma$ defined as follows:

$$
G=P_{c r}\left(\left[\theta_{1} / \theta_{2} / \ldots / \theta_{N}\right]_{O P T I}\right)-P_{c r}\left(\left[55_{N}\right]\right) \text { and } \gamma=G / P_{c r}\left(\left[55_{N}\right]\right)
$$


where $P_{c r}\left(\left[55_{N}\right]\right)$ corresponds to the limit of stability presented in table 3 . The buckling pressure increase calculated using the FE models appears to be substantial.

As shown in Figures 5 and 6 , it is worth noting that the optimization procedure leads to typical, similar $\left[90_{N 1} / \alpha / 30_{N 2} / \beta / 90_{N 3}\right]$ laminations, where $\alpha$ and $\beta$ indicate plies of transition zones. However, the optimized solutions obtained using the Sanders-type model provide lower buckling pressure values than those obtained using the CT3 model. Thus, in spite of small differences on the buckling pressure values between the Sanders-type and the CT3 models (see Table 2 and Figures 5 and 6 ), the optimization results appear to be sensitive to the shear transverse effects, especially for the thicker cylinders.

Additional buckling calculus, concerning the optimized stacking sequences presented in Figure 6 have also been performed using the Adina and Solvia FEM codes. The results, presented in Tables 4 and 5 , confirm significant buckling pressure increases. Moreover, we can notice that these critical loads are greater for all cylinders than the stability limits of $\left[90_{M} / \theta_{M}\right]$ laminations studied in [PAP 98].

\begin{tabular}{|c|c|c|c|}
\hline cylinder & $\boldsymbol{P}_{\boldsymbol{c r}}(\mathbf{M P a})$ & $\boldsymbol{G}(\mathbf{M P a})$ & $\boldsymbol{\gamma ( \boldsymbol { \% } )}$ \\
\hline \hline $\mathbf{1}$ & 30.0 & 8.7 & 40.8 \\
\hline $\mathbf{2}$ & 54.7 & 13.3 & 32.1 \\
\hline $\mathbf{3}$ & 89.6 & 21.4 & 31.4 \\
\hline $\mathbf{4}$ & 133.4 & 31.4 & 30.8 \\
\hline
\end{tabular}

Table 4. Results obtained using Adina

\begin{tabular}{|c|c|c|c|}
\hline cylinder & $\boldsymbol{P}_{\boldsymbol{c r}}(\mathbf{M P a})$ & $\boldsymbol{G}(\mathbf{M P a})$ & $\boldsymbol{\gamma}(\boldsymbol{\%})$ \\
\hline \hline $\mathbf{1}$ & 29.1 & 10.1 & 53.2 \\
\hline $\mathbf{2}$ & 56.4 & 17.8 & 46.1 \\
\hline $\mathbf{3}$ & 95.6 & 29.8 & 45.3 \\
\hline $\mathbf{4}$ & 145.0 & 45.8 & 46.2 \\
\hline
\end{tabular}

Table 5. Results obtained using Solvia

In the case of cylinder number 6 , an additional manufacturing requirement has been included in the optimization problem: five successive plies whose angle values are less than $75^{\circ}$ are compulsorily followed by a $90^{\circ}$ ply in order to compact the resin and so therefore to regularize the fiber ratio. Figure 7 presents the corresponding result, obtained using the CT3 model. In spite of this additional constraint, the $\left[90_{N 1} / \alpha / 30_{N 2} / \beta / 90_{N 3}\right]$ pattern is preserved. 


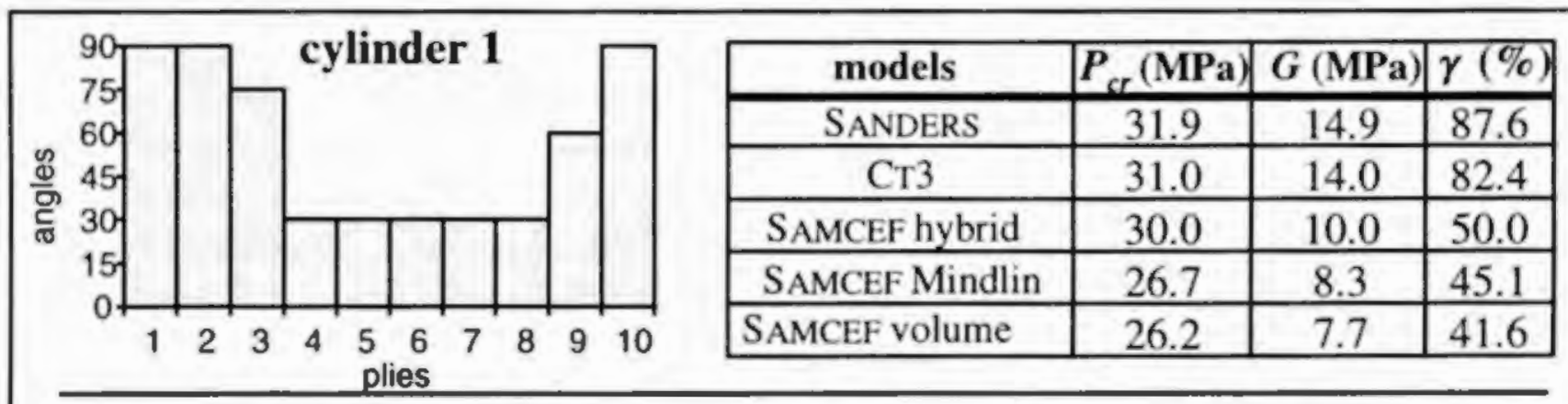

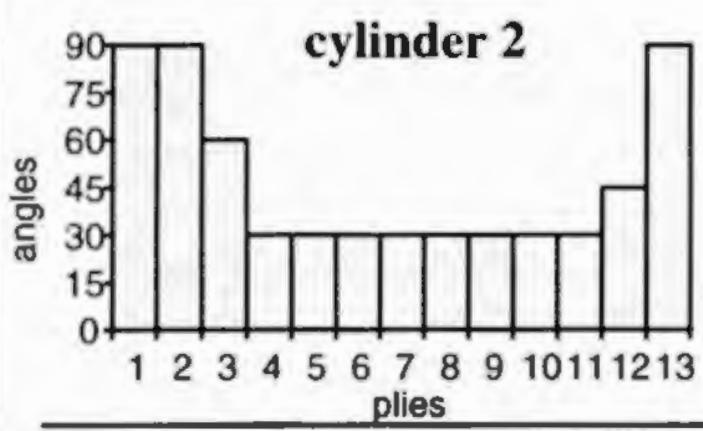

\begin{tabular}{|c|c|c|c|}
\hline models & $\boldsymbol{P}_{c r}(\mathrm{MPa})$ & $G(\mathrm{MPa})$ & $\boldsymbol{\gamma}(\boldsymbol{\%})$ \\
\hline SANDERS & 54.1 & 23.0 & 74.0 \\
\hline CT3 & 53.2 & 22.1 & 71.1 \\
\hline SAMCEF hybrid & 52.8 & 11.1 & 26.6 \\
\hline SAMCEF Mindlin & 44.7 & 9.5 & 27.0 \\
\hline SAMCEF volume & 44.0 & 8.4 & 23.6 \\
\hline
\end{tabular}

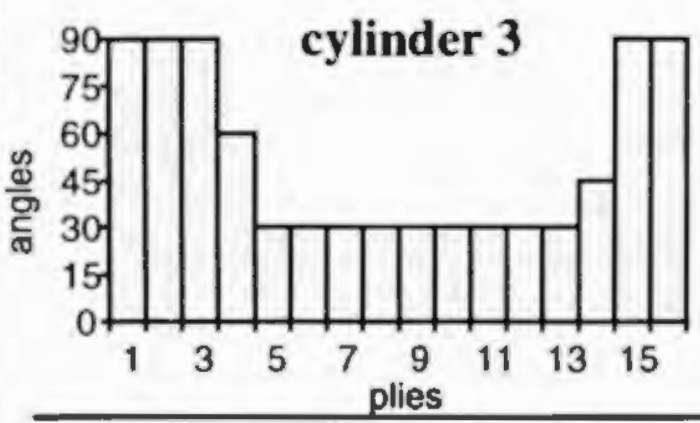

\begin{tabular}{|c|c|c|c|}
\hline models & $\boldsymbol{P}_{\text {cr }}(\mathbf{M P a})$ & $\boldsymbol{G}(\mathbf{M P a})$ & $\boldsymbol{\gamma}(\boldsymbol{\%})$ \\
\hline SANDERS & 81.7 & 30.5 & 59.6 \\
\hline CT3 & 81.3 & 29.9 & 58.2 \\
\hline SAMCEF hybrid & 97.4 & 32.0 & 48.9 \\
\hline SAMCEF Mindlin & 77.1 & 19.6 & 34.1 \\
\hline SAMCEF volume & 78.0 & 18.2 & 30.4 \\
\hline
\end{tabular}

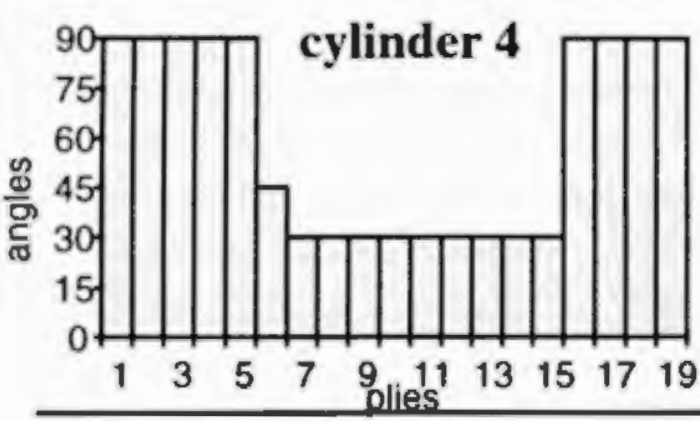

\begin{tabular}{|c|c|c|c|}
\hline models & $\boldsymbol{P}_{c r}(\mathbf{M P a})$ & $\boldsymbol{G}(\mathbf{M P a})$ & $\boldsymbol{\gamma}(\boldsymbol{\%})$ \\
\hline SANDERS & 119.0 & 40.5 & 51.6 \\
\hline CT3 & 119.4 & 40.5 & 51.3 \\
\hline SAMCEF hybrid & 127.3 & 36.0 & 39.4 \\
\hline SAMCEF Mindlin & 113.2 & 29.8 & 35.7 \\
\hline SAMCEF volume & 98.5 & 22.7 & 29.9 \\
\hline
\end{tabular}

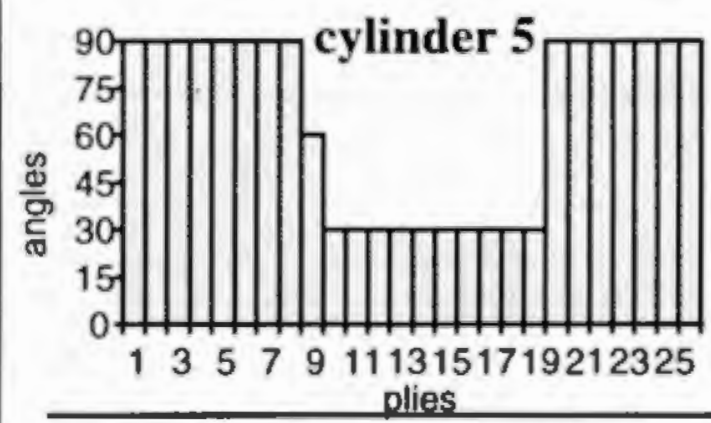

\begin{tabular}{|c|c|c|c|}
\hline models & $\boldsymbol{P}_{c r}(\mathbf{M P a})$ & $\boldsymbol{G}(\mathbf{M P a})$ & $\boldsymbol{\gamma}(\boldsymbol{\%})$ \\
\hline SANDERS & 247.6 & 74.3 & 42.9 \\
\hline CT3 & 246.8 & 72.5 & 41.6 \\
\hline SAMCEF hybrid & 231.7 & 56.4 & 32.2 \\
\hline SAMCEF Mindlin & 177.0 & 31.9 & 22.0 \\
\hline SAMCEF volume & 154.7 & 21.1 & 15.8 \\
\hline
\end{tabular}

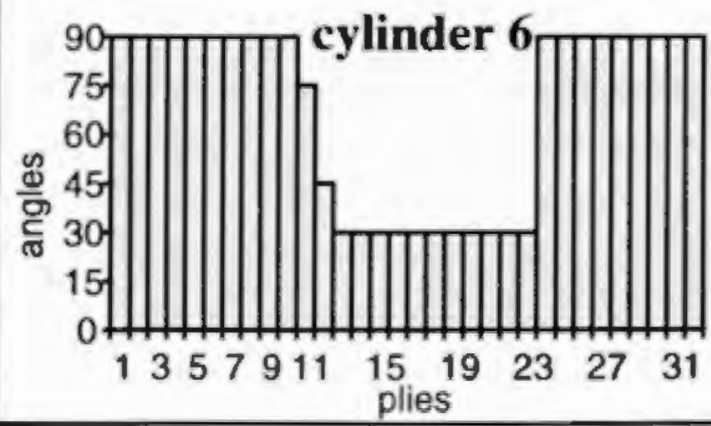

\begin{tabular}{|c|c|c|c|}
\hline models & $\boldsymbol{P}_{c r}(\mathbf{M P a})$ & $\boldsymbol{G}(\mathbf{M P a})$ & $\boldsymbol{\gamma}(\boldsymbol{\%})$ \\
\hline SANDERS & 411.1 & 115.8 & 39.2 \\
\hline CT3 & 402.8 & 105.7 & 35.6 \\
\hline SAMCEF hybrid & 362.1 & 86.3 & 31.3 \\
\hline SAMCEF Mindlin & 241.9 & 34.4 & 16.6 \\
\hline SAMCEF volume & 217.5 & 22.3 & 11.4 \\
\hline
\end{tabular}

Figure 5. Optimized laminations obtained using the Sanders-type model 


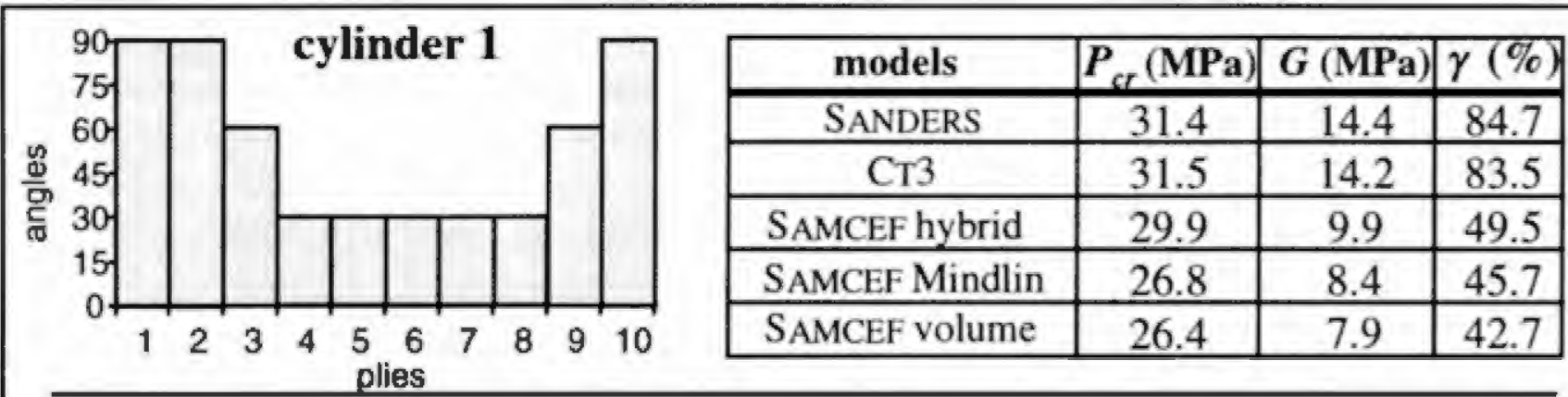

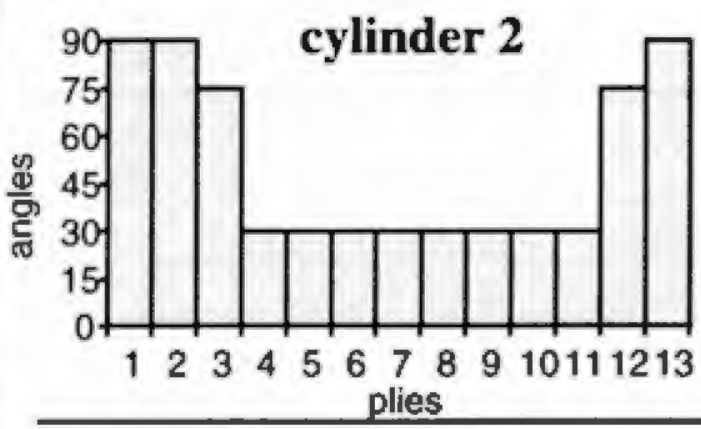

\begin{tabular}{|c|c|c|c|}
\hline models & $\boldsymbol{P}_{\text {cr }}(\mathbf{M P a})$ & $\boldsymbol{G}(\mathbf{M P a})$ & $\boldsymbol{\gamma}(\boldsymbol{\%})$ \\
\hline SANDERS & 53.8 & 22.7 & 73.0 \\
\hline CT3 & 53.3 & 22.2 & 71.4 \\
\hline SAMCEF hybrid & 59.5 & 17.8 & 42.7 \\
\hline SAMCEF Mindlin & 48.7 & 13.5 & 38.4 \\
\hline SAMCEF volume & 48.1 & 12.5 & 35.1 \\
\hline
\end{tabular}

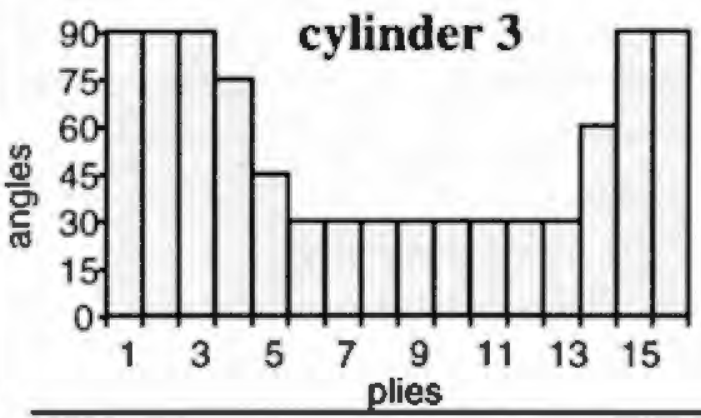

\begin{tabular}{|c|c|c|c|}
\hline models & $\boldsymbol{P}_{c r}(\mathbf{M P a})$ & $\boldsymbol{G}(\mathbf{M P a})$ & $\boldsymbol{\gamma}(\boldsymbol{\%})$ \\
\hline SANDERS & 81.6 & 30.4 & 59.4 \\
\hline CT3 & 81.4 & 30.0 & 58.4 \\
\hline SAMCEF hybrid & 95.4 & 30.0 & 45.9 \\
\hline SAMCEF Mindlin & 79.1 & 21.6 & 37.6 \\
\hline SAMCEF volume & 80.3 & 20.5 & 34.3 \\
\hline
\end{tabular}

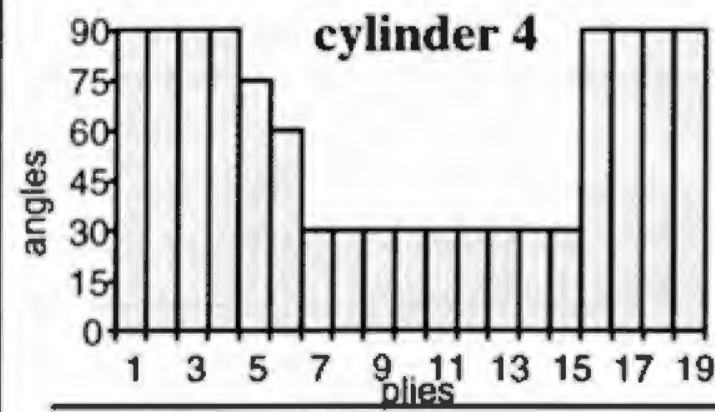

\begin{tabular}{|c|c|c|c|}
\hline models & $\boldsymbol{P}_{c r}(\mathbf{M P a})$ & $\boldsymbol{G}(\mathbf{M P a})$ & $\boldsymbol{\gamma}(\boldsymbol{\%})$ \\
\hline SANDERS & 118.8 & 40.3 & 51.3 \\
\hline CT3 & 119.5 & 40.6 & 51.5 \\
\hline SAMCEF hybrid & 126.9 & 35.6 & 39.0 \\
\hline SAMCEF Mindlin & 113.4 & 30.0 & 36.0 \\
\hline SAMCEF volume & 98.6 & 22.8 & 30.1 \\
\hline
\end{tabular}

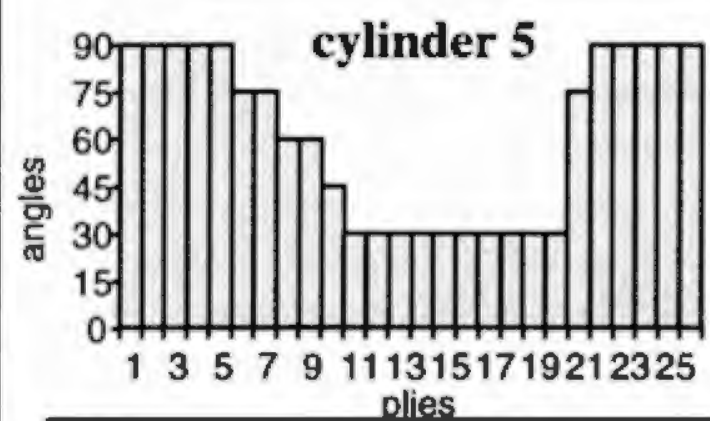

\begin{tabular}{|c|c|c|c|}
\hline models & $\boldsymbol{P}_{c \boldsymbol{r}}(\mathbf{M P a})$ & $\boldsymbol{G}(\mathbf{M P a})$ & $\boldsymbol{\gamma}(\boldsymbol{\%})$ \\
\hline SANDERS & 246.2 & 72.9 & 42.1 \\
\hline CT3 & 247.3 & 73.0 & 41.9 \\
\hline SAMCEF hybrid & 238.6 & 63.3 & 36.1 \\
\hline SAMCEF Mindlin & 188.2 & 43.1 & 29.7 \\
\hline SAMCEF volume & 164.9 & 31.3 & 23.4 \\
\hline
\end{tabular}

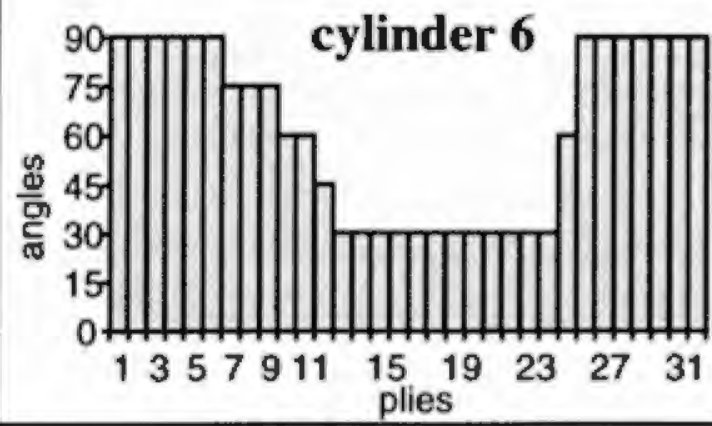

\begin{tabular}{|c|c|c|c|}
\hline models & $\boldsymbol{P}_{c r}(\mathbf{M P a})$ & $\boldsymbol{G}(\mathbf{M P a})$ & $\boldsymbol{\gamma}(\boldsymbol{\%})$ \\
\hline SANDERS & 407.7 & 112.4 & 38.1 \\
\hline CT3 & 405.5 & 108.4 & 36.5 \\
\hline SAMCEF hybrid & 371.8 & 96.0 & 34.8 \\
\hline SAMCEF Mindlin & 259.4 & 51.9 & 25.0 \\
\hline SAMCEF volume & 232.7 & 37.5 & 19.2 \\
\hline
\end{tabular}

Figure 6. Optimized laminations obtained using the CT3 model 


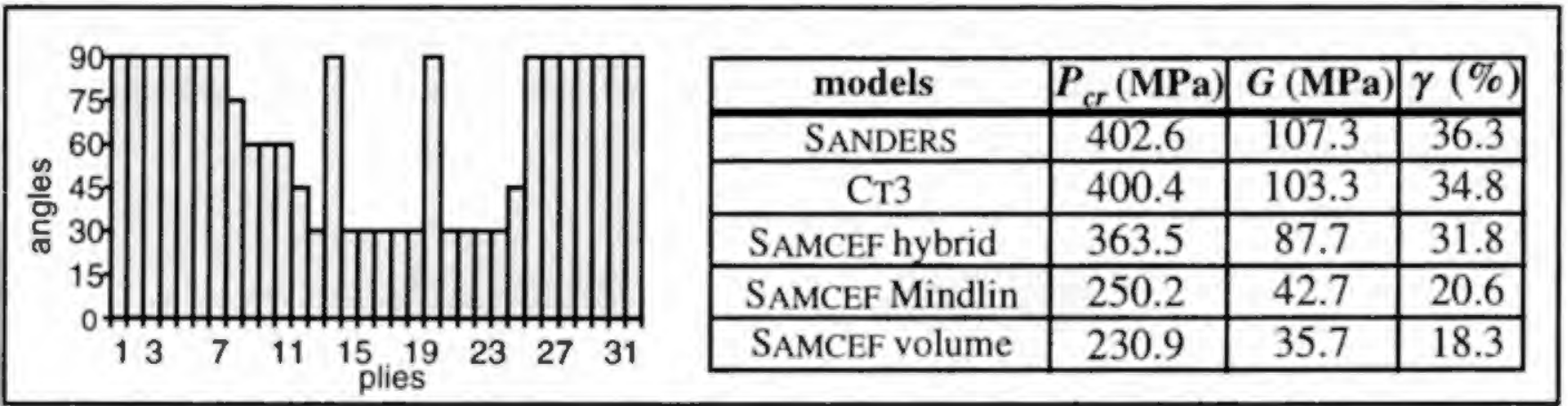

Figure 7. Optimized lamination including the fiber regularization constraint

\subsubsection{Unconstrained solutions}

Additional calculus have been carried out in order to improve the influence of the manufacturing constraints. The optimization of cylinders was then performed for ply angles changing from $0^{\circ}$ to $90^{\circ}$ by step of $1^{\circ}$. The additional fiber regularization manufacturing constraint previously considered for the 32-ply cylinder, was not included. Figure 8 presents the best stacking sequences obtained (after 15 GA runs) using the CT3 model. The indicated $\gamma$ values are calculated using the Samcef Mindlin shell model. These optimized laminations are very similar to the ones obtained previously, always leading to $\left[90_{N 1} / \alpha / 0_{N 2} / \beta / 90_{N 3}\right]$ laminations. The $\gamma$ values are slightly greater than those obtained including manufacturing limitations. As noticed in $\S 4.2$, the results corresponding to the Sanders-type model (not presented) also lead to lower buckling pressure values, especially for the thicker cylinders.

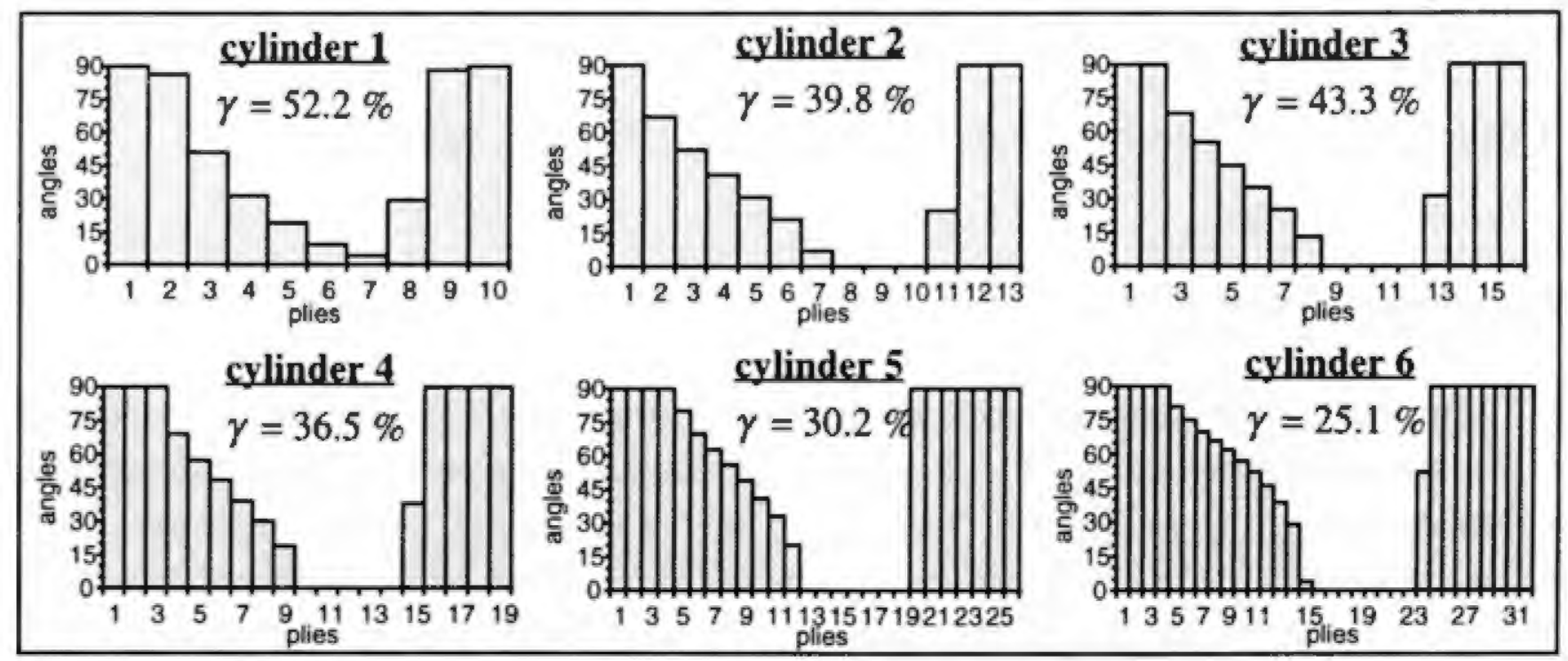

Figure 8. Unconstrained optimized solutions

\subsubsection{Interpretation}

It may be noted that stacking sequence patterns like $\left[90_{N 1} / \alpha / 30_{N 2} / \beta / 90_{N 3}\right]$ or $\left[90_{N 1} / \alpha / 0_{N 2} / \beta / 90_{N 3}\right]$ increase the bending stiffness of the shell in the $(y, z)$ plane. 
Figure 9 presents the similarity between a $\left[90_{N 1} / 0_{N 2} / 90_{N 3}\right]$ lamination pattern and an I-section beam. Thus, considering this analogy, we can conclude that the optimized laminations act as circumferential stiffeners.
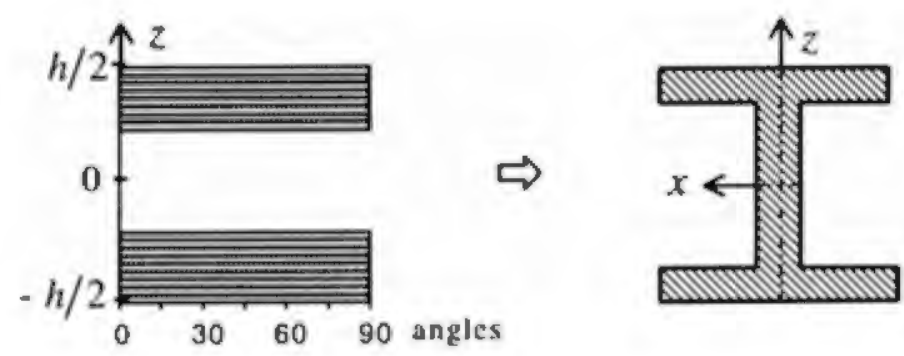

Figure 9. Analogy with an I-section beam

The search for the worst stacking sequences, providing the lowest buckling pressures, was performed as well in order to verify how distant they are from the optimized solutions. For ply angles changing from $0^{\circ}$ to $90^{\circ}$ by step of $1^{\circ}$, the worst solutions obtained always give $\left[0_{N}\right]$ laminations. Table 10 presents the corresponding buckling pressure and the $\gamma$ values (then negative) calculated using the Samcef Mindlin shell model. These results complete the previous interpretation and the analogy presented in Figure 9: the worst laminations $\left[0_{N}\right]$ provide the lowest bending stiffness in the $(y, z)$ plane and consequently lead to the lowest buckling pressure values.

\begin{tabular}{|c||c|c|c|c|c|c|}
\hline cylinder n $^{\circ}$ & $\mathbf{1}$ & $\mathbf{2}$ & $\mathbf{3}$ & $\mathbf{4}$ & $\mathbf{5}$ & $\mathbf{6}$ \\
\hline $\boldsymbol{P}_{\boldsymbol{c r}}(\mathbf{M P a})$ & 4.7 & 8.1 & 13.0 & 19.3 & 39.6 & 63.4 \\
\hline $\boldsymbol{\gamma}(\boldsymbol{\%})$ & -74.5 & -77.0 & -77.4 & -76.9 & -72.7 & -69.4 \\
\hline
\end{tabular}

Table 6. Buckling pressure and $\gamma$ loss values for the $\left[O_{N}\right]$ cylinders

\subsection{Performances of $G A$}

This paragraph concerns the study of performances of the GA procedure for calculations performed in $\S 4.2 .1$ and the reproducibility of the corresponding solutions presented in Figures 5 and 6 . The manufacturer angle constraints (cf. $\S$ 4.2.1), limit the space design of the optimization problem to $5^{N}$ different lamination solutions for a $N$-plies cylinders. Table 7 presents these cardinality values (i.e. the number of different possible solutions) for each cylinder thickness case. The number of individuals and generations used for the GA code and the corresponding CPU time (on a Sun Ultrasparc workstation) are also indicated. It is worth noting that the ratio between the number of buckling analyses realized during a GA run and the cardinality of the discrete optimization problem is about $0.1 \%$ for the cylinder number 1 and less than $3.5 \cdot 10^{-16} \%$ for the cylinder number 6 . 


\begin{tabular}{|c||c|c|c|c|c|c|}
\hline cylinder $^{\circ}$ & $\mathbf{1}$ & $\mathbf{2}$ & $\mathbf{3}$ & $\mathbf{4}$ & $\mathbf{5}$ & $\mathbf{6}$ \\
\hline Cardinality $^{\circ}$ & $9.8 \cdot 10^{6}$ & $1.2 \cdot 10^{9}$ & $1.5 \cdot 10^{11}$ & $1.9 \cdot 10^{13}$ & $1.5 \cdot 10^{18}$ & $2.3 \cdot 10^{22}$ \\
\hline number of individuals & 50 & 60 & 70 & 80 & 90 & 100 \\
\hline number of generations & 200 & 300 & 400 & 500 & 600 & 800 \\
\hline CPU time (minutes) & 9 & 18 & 31 & 46 & 64 & 98 \\
\hline
\end{tabular}

Table 7. Cardinality and population parameters of the $G A$

As mentioned in $\$ 4.2 .1,20$ successive runs of GA have been performed for each cylinder case. Table 8 presents the average fitness (and the corresponding standard deviation) values of the best individuals obtained for these 20 optimization calculations performed using the CT3 model. The average values appear to be very close to the ones presented in Figure 6 . The corresponding standard deviation values indicated very small discrepancies. Moreover, all of the best laminations obtained for each of the 20 runs are always $\left[90_{N 1} / \alpha / 30_{N 2} / \beta / 90_{N 3}\right]$ lamination patterns, having few numbers of angle value differences with respect to the solutions presented in Figure 6. The results deduced from the calculation using the Sanders-type model are similar. Thus, the GA procedure always provides similar solutions by exploring a very small number of possible configurations. The $\left[90_{N 1} / \alpha / 30_{N 2} / \beta / 90_{N 3}\right]$ laminations appear to benefit from a high reproducibility.

\begin{tabular}{|c||c|c|c|c|c|c|}
\hline cylinder $\mathbf{n}^{\circ}$ & $\mathbf{1}$ & $\mathbf{2}$ & $\mathbf{3}$ & $\mathbf{4}$ & $\mathbf{5}$ & $\mathbf{6}$ \\
\hline Fitness average & 31.46 & $53.2 \mathrm{l}$ & 80.95 & 118.70 & 246.41 & 404.52 \\
standard deviation & 0.14 & 0.18 & 0.66 & 0.95 & 1.02 & 1.07 \\
\hline
\end{tabular}

Table 8. Statistical results of the GA runs

\subsection{Robustness of the optimized solutions}

\subsubsection{Sensitivity to material parameters}

The experimental difficulties in characterizing properly the material of the structures under consideration [DAV 96] induce doubts about the exactness of the orthotropic characteristic values presented in $\S 4.1$. In order to evaluate numerically the influence of these uncertainties, 50 runs of GA, including the angle constraints (cf. § 4.2.1) have been carried out for each cylinder case. The CT3 shell model is used. Each of the nine orthotropic parameters is randomly and independently generated for every calculation within the following range of values (modulus in $\mathrm{GPa})$ :

$$
\begin{gathered}
102.9 \leq E_{1} \leq 156 ; 8.44 \leq E_{2} \leq 9.65 ; 5.93 \leq E_{3} \leq 6.57 \\
5.33 \leq G_{12} \leq 5.473 ; 2.31 \leq G_{13} \leq 2.8 ; 2.11 \leq G_{23} \leq 3.925
\end{gathered}
$$




$$
0.27 \leq v_{12} \leq 0.277 ; 0.295 \leq v_{13} \leq 0.34 ; 0.471 \leq v_{23} \leq 0.492
$$

The interval values are related to the study presented in [CHA 99] and correspond to variations of the fiber ratio and the longitudinal fiber Young's modulus. Figure 10 presents the average and the corresponding standard deviation values of the lamination angles for the 50 best solutions obtained for each cylinder case. As shown, for example, for the optimized lamination of the cylinder 1 , only the plies number 3 and 9 vary (equal to 45,60 or $75^{\circ}$ ). Thus, the $\left[90_{N 1} / \alpha / 30_{N 2} / \beta / 90_{N 3}\right]$ typical laminations are always preserved. Such a lamination pattern appears to be stable and robust in spite of uncertainties over material characteristics.

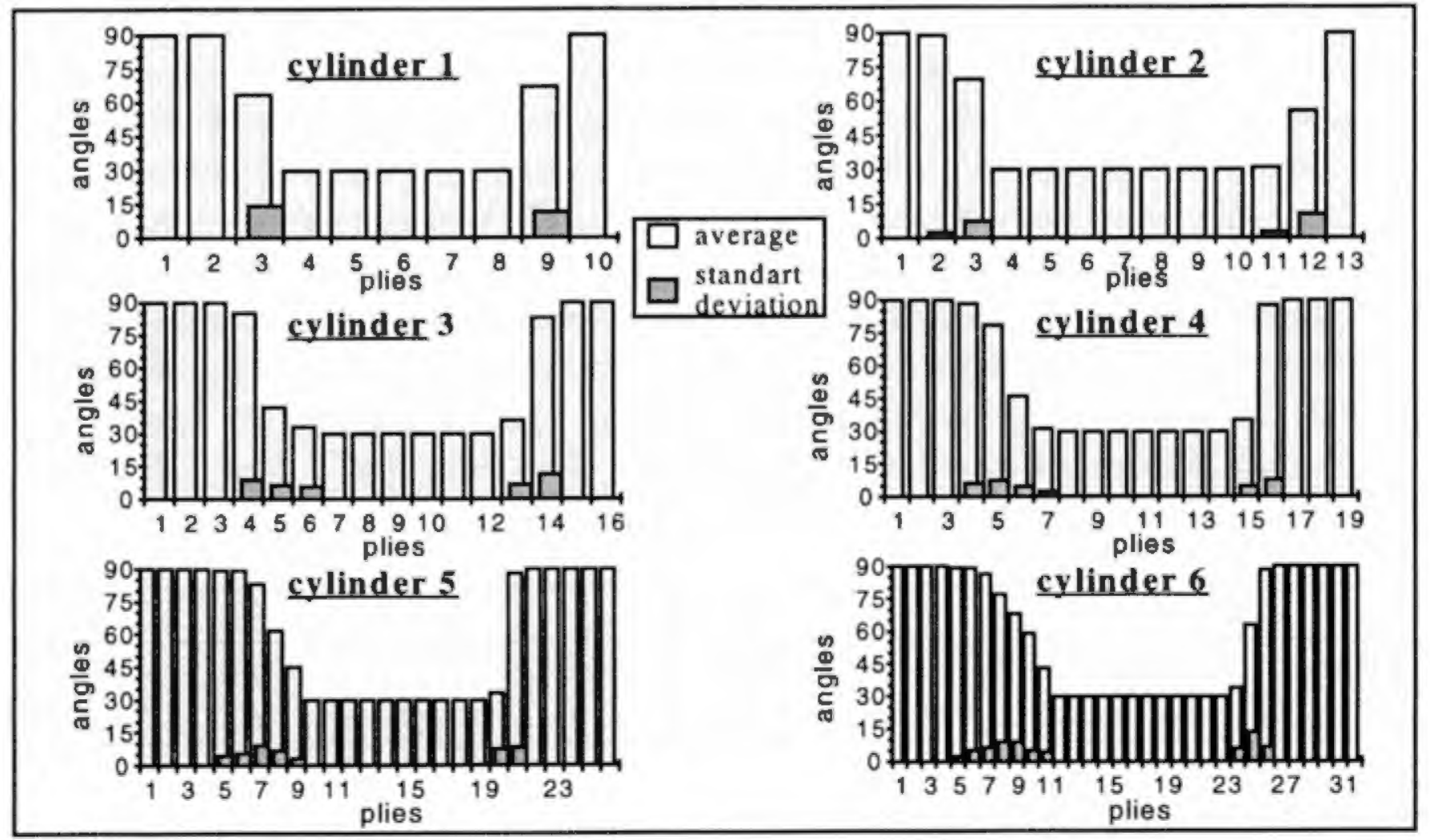

Figure 10. Mechanical characteristic influence

\subsubsection{Influence of the geometrical imperfections}

The study of geometrical imperfection influences on optimized laminations is presented for the thinner cylinders numbered 1 and 2. Additional calculations including imperfection values have been performed using the CT3 model. Three values of $\tilde{h}$ (which is the global equivalent root-mean-square value of imperfections on the external surface of cylinders [BAR 83]) are investigated : 0.5, 1 and $2 \mathrm{~mm}$. The optimized solutions obtained are presented in Figure 11. Some angle variations are observed only in the $\alpha$ and $\beta$ transition zones with respect to the $\left[90_{N 1} / \alpha / 30_{N 2} /\right.$ $\beta / 90_{N 3}$ ] patterns presented in Figure 6. 


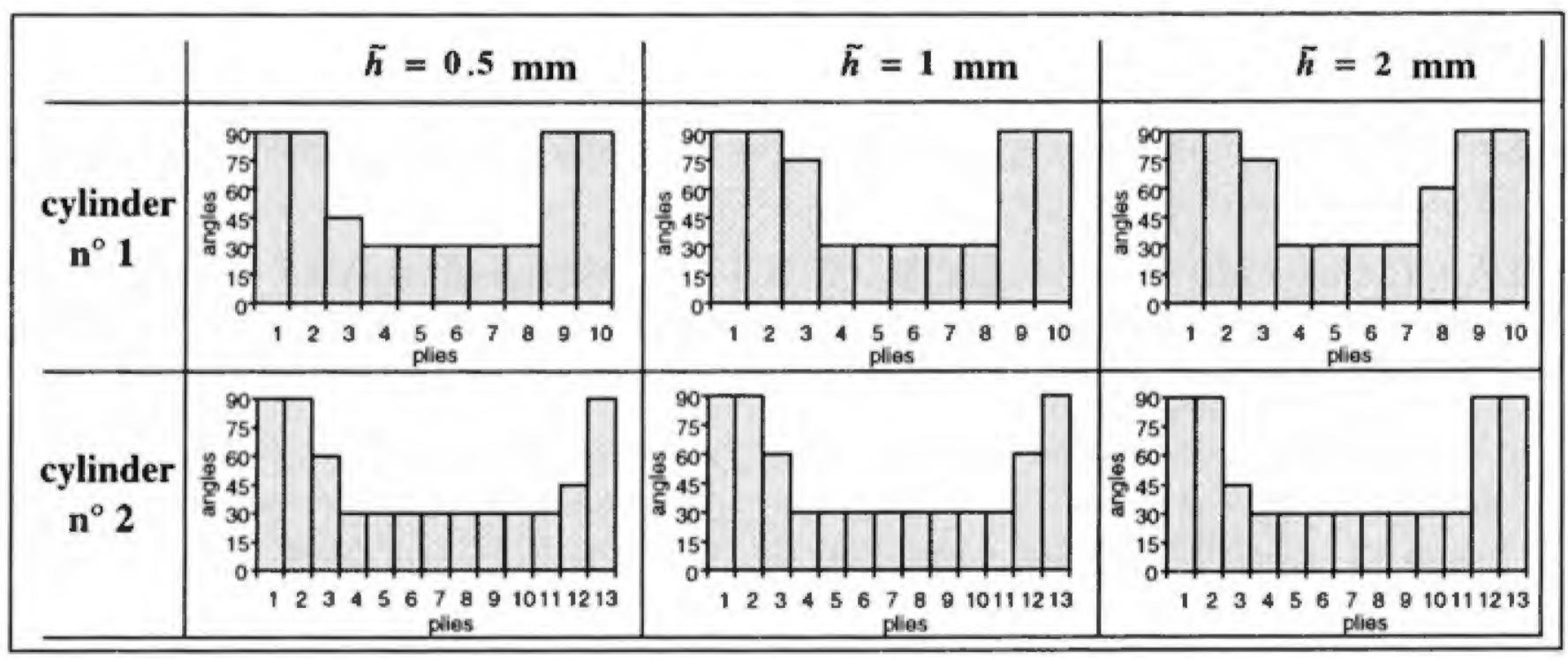

Figure 11. Optimized solutions including geometrical imperfections

\section{Conclusion}

An optimal design tool for submarine composite, laminated cylinders exposed to instability risk has been developed using a genetic algorithm coupled with analytical buckling models. It allows the optimization of the stacking sequences in order to increase the buckling pressure values. Numerical applications concerning IFREMER's studies have been performed including the manufacturing constraints. The optimized cylinder laminations are based on a typical pattern $\left[90_{N 1} / \alpha / 30_{N 2} / \beta /\right.$ $90_{N 3}$ ] similar for all analyzed examples. The $\mathrm{FE}$ modeling has confirmed the significant increases (exceeding several tens of percent) of buckling loads of optimized stacking sequences with respect to classical $\left[55_{N}\right]$ laminations. Additional studies have confirmed that such laminations of $\left[90_{N 1} / \alpha / 30_{N 2} / \beta / 90_{N 3}\right]$ type are robust and preserved even if mechanical properties are uncertain and if structures are geometrically imperfect. Moreover, the numerical applications have shown the usefulness of the GA optimization procedure. Large discrete design spaces were processed and solved in acceptable CPU times.

An experimental study concerning the carbon reinforced epoxy resin and having the optimized laminations presented in this paper, is currently being performed in IFREMER laboratories. Some buckling tests on glass/epoxy cylinders with $\left[55_{N}\right]$ and optimized stacking sequences are also being performed on a special testing device described in [GIN 99]. The first results indicate a substantial increase of buckling pressure for the optimized laminations.

Acknowledgments

The authors wish to thank the "Conseil Régional de Bretagne" and the MAS3CT97-0091 project of the European Community MAST program for their support. 


\section{References}

[BAR 83] BARBE J., Structures coques - équations générales et stabilité, ENSAE, Toulouse, 1983.

[CHA 99] Chauchot P., Le Flour D., Warin M., "Numerical study of a scaled-down version of an Autonomous Underwater Vehicle", report DITI/GO/MSG 99.46, IFREMER, February 1999.

[DaV 96] Davies P., Choqueuse D., Riou L., Warnier P., Jégou P., Rolin J.F., Bigourdan B., Chauchot P., «Matériaux composites pour véhicule sous-marin 6000 mètres », Journées Nationales Composites 10, Vol. 1, p. 525-535, AMAC, 29-31 octobre 1996, Paris.

[DVO 96] Dvorak G.J., Prochazka P., "Thick-walled composites cylinders with optimal fiber prestress", Composites Structures, Vol. 27b, p. 643-649, 1996.

[GAY 97] GAY D., Matériaux composites, $4^{\mathfrak{c}}$ édition revue et augmentée, Hermès, Paris, 1997.

[GIN 99] Gineste B., Grohens A., Messager T.,«Essais en flambage de tubes composites sous pression externe », $14^{\text {ème }}$ Congrès Français de Mécanique, AUM-AFM, 30 août - 3 septembre 1999, Toulouse.

[GOL 94] GOLDBERG D.E., Algorithmes Génétiques, exploration, optimisation et apprentissage automatique, Addison-Wesley France, 1994.

[GRA 95] Graham D., "Composite pressure hulls for deep ocean submersibles", Composites Structures, Vol. 32, p. 331-343, 1995.

[GUG 95] GugGENBERGER W., " Buckling and postbuckling of imperfect cylindrical shells under external pressure", Thin-Walled Structures, Vol. 23, p. 351-366, 1995.

[MES 99] MESSAGER T., "Buckling of imperfect laminated cylinders under hydrostatic pressure", Engineering Transactions, submitted to publication, June 1999.

[MIC 96] MichalewiCZ Z., Genetic algorithms + data structures = evolution programs, third, revised and extended edition, Springer Verlag Edition, Berlin, Heidelberg, 1996.

[PAP 98] Papazoglou V.J., Tsouvalis N.G., Zaphiratou A.A., "Parametric study of small scale cylinders under hydrostatic load: flat rigid end closures", MAST III project, report STL-073-F-98, National Technical University of Athens, July 1998.

[PYR 98] Pyrz M., Messager T., Coloos J., "Optimal design of plate structures using genetic algorithm", $2^{\text {nd }}$ Int. Conf. on Integrated Design and Manufacturing in Mechanical Engineering, Vol. 1, p.51-58, May 27-29, Compiègne, 1998.

[SEB 96] Sebag M.,S Schoenauer M., "Contrôle d'un algorithme génétique », Revue d'Intelligence Artificielle, Vol. 10, $\mathrm{n}^{\circ}$ 2-3, p. 389-428, Hermès, Paris, 1996.

[TAB 97] TABIEI A., Simitses G., "Imperfection sensitivity of shear deformable moderately thick laminated cylindrical shells", Computers \& Structures, Vol. 62, n 1, p. 165-174, 1997. 
[TEN 71] Tennyson R.C., Chan K.H., Muggeridge D.B., "The effect of axisymetric shape imperfections on the buckling of laminated anisotropic circular cylinders", CASI Transactions, Vol. 4, $\mathrm{n}^{\circ}$ 2, p. 131-139, 1971

[VIN 92] VINSON J.R., The behaviour of shells composed of isotropic and composite materials, Kluwer Academic Publishers, 1992.

[YAN 97] YAN J., KIONG SOH C., "Structural optimization by genetic algorithm with tournament selection", J. of Computing in Civil Engineering, p. 195-200, July 1997. 